\title{
Sacral Saddle Block for Day Care and Ambulatory Surgery in Anorectal Procedure.
}

\author{
Radhashyam Paria ${ }^{1}$, Smarajit Surroy $^{1}$, Mousumi Majumder ${ }^{1}$, Baishakhi Paria ${ }^{2}$, \\ Soma Sengupta, Anshuman Paria ${ }^{3}$, Goutam Das ${ }^{4}$ \\ ${ }^{1}$ Department of Anesthesiology, Howrah Orthopedic Hospital, Eastern Railways, Kolkata, India \\ ${ }^{2}$ Department of Community Medicine, National Medical College, Kolkata, India \\ ${ }^{3}$ Department of Neonatology, SSKM Hospital, Kolkata, India \\ ${ }^{4}$ Department of Pediatric Medicine, North Bengal Medical College, Siliguri, India
}

\begin{abstract}
:
Background: In current era of high costing health care, the saddle block, a segmental block for lower four sacral spinal roots, is an essential method for day care surgery in anorectal surgical procedure.

Aims: We designed our study to find out an easy way for specific saddle block through sacral dorsal foramens to make it suitable for day care and ambulatory anesthesia.

Methods: We performed sacral saddle block through $2^{\text {nd }}$ dorsal foramen of sacrum injecting intrathecally 0.75 $\mathrm{ml}$ of $0.5 \%$ injection bupivacaine.

Results: Posterior surface of lower limb including perineum, innervated by sacral component of spinal roots became painless. No motor block detected, only dilatation of anal sphincter was present.

Conclusion: With limited involvement of sacral component of spinal roots and comfort to patient, sacral saddle block is highly suitable for anorectal surgical procedure without hemodynamic instability.
\end{abstract}

\section{Introduction}

In current era of high costing health care and modern development of technological implication in surgery, any technical change reducing medical expenditure for high quality of anesthesia and surgery is always a welcome move. Such move has been celebrated by introduction of ambulatory surgery and anesthesia reducing hospital stay. Anesthesiologists are also motivated to change their technique to fulfill the demand of day care surgery. On the other hand, it is an universal acceptable opinion that minimal involvement of body physiology contributes maximal benefits to patients. On such focus, intrathecal administration of minimal dose of the local anesthetic at the bottom of the dural sac with sufficient enough to work out the surgical procedure is highly beneficial to patients in connection to hemodynamic stability and early ambulation. For achieving above benefits, our present study is designed to introduce sacral saddle block through 2nd dorsal foramen of sacrum to evaluate its merits and demerits in anorectal surgical procedure.

\section{Methods}

With approval of medical ethical review board and written informed consent for procedure and study, 30 patients, aged between 20 to 70 years, with ASA physical status class I and II, undergoing anorectal surgery during the period January 2013 to December 2013 were included in this study . All patients were subjected to preoperative assessment to eliminate the cases, contraindicated for spinal anesthesia.

In the operation theatre, after establishment of intravenous infusion, and usual standard aseptic preparation in sitting position of patient on operation table, 2nd dorsal foramen of sacrum were identified with help of anatomical land marks. First of all, the spine of forth lumbar vertebra $\left(\mathrm{L}_{4}\right)$ and tip of coccyx were identified and their mid-point was found out. This mid-point denoted the position of spine of the third sacral vertebra $\left(\mathrm{S}_{3}\right)$. The mid-point of $\mathrm{L}_{4}$ and $\mathrm{S}_{3}$ indicated the position of the spine of the first sacral vertebra. The midpoint of $S_{1}$ and $S_{3}$ pointed the position of the spine of the second sacral vertebra $\left(S_{2}\right) .1 .5 \mathrm{~cm}$ lateral and $1.5 \mathrm{~cm}$ caudal from each point $\left(\mathrm{S}_{1}, \mathrm{~S}_{2}\right)$ were taken as the position of the respective foramen.

The anatomical landmarks detected in above way, can be further confirmed by the relationship of other structures. $\mathrm{L}_{4}$ is situated on the line joining the iliac crests. The tip of coccyx is at the level of femoral accetebulum. $\mathrm{S}_{2}$ is at the level of the posterior superior iliac spine which is sometimes manifested as dimple of skin. $S_{3}$ spine is at yhe level posterior inferior iliac spine.

After proper identification of foramen, the sacral spinal anesthesia was attempted with simple spinal needle (Spinocan ${ }^{\circledR} 26$ Ga. x 31/2 in. (90 mm) Spinal Needle, B. Braun Medical Inc) through 2nd dorsal foramen of sacrum ${ }^{12}$. Subarachnoid space was identified by appearance of clear free flow of cerebrospinal fluid through spinal needle and $0.75 \mathrm{ml}$ of $0.5 \%$ Bupivacaine (heavy) was injected to it. Prior to surgery, every patient was 
monitored for non-invasive blood pressure, electrocardiogram, heart rate, and oxygen concentration and repeated every 5 minutes. Immediate after completion of intrathecal procedure, we turned the patient supine and put under monitoring system.

After anesthesia, all patients were subjected to assess the motor block by modified Bromage scale, lifting their legs and eliciting movements of individual joints of lower limbs. Both anterior and posterior surfaces of lower limbs including perineum were estimated for sensory block by pinprick method in supine position.

Time of onset of sensory block, is defined as the interval between intrathecal injection and bilateral loss of sensation. Similarly duration of sensory block is defined as the time interval between intrathecal injection and complete recovery of sensation. All patients were able to lift up their legs after saddle block and also after surgery. Only complete relaxation of anal sphincter was found at the time of rectal examination by surgeon. After surgery, all patients were able to move from operation table to transport trolley without help and even to walk.

Day care surgery and ambulatory surgery are surgeries from which patients recover and return to home within 24 hours and 12 hours respectively Data collected for statistical analysis by appropriate statistical methods.

\section{Results}

30 patients of average age $49.70 \pm 12.22$ years, average weight $58.23 \pm 9.71 \mathrm{~kg}$ and average height $153.00 \pm 3.96 \mathrm{cms}$ underwent anorectal surgical procedure with sacral saddle block and sensory block was limited to posterior surface of lower limb including perineal skin within 6 minutes and lasted for approximately 3 hours. Extension and flexion movements of hip, knee and ankle joints remained unaffected. Anal sphinter became dilated. All patient felt comfort during and after surgery. No hypotension developed. No bradycardia developed. With uneventful post-operative observation, the patient was discharged home on the same day. Patients selected for day care surgery needed some degree of focused post-operative monitoring for a few hours.

\section{Discussion}

The modern development of technological implication in the field of surgical procedure has instituted a tremendous growth in surgical techniques applicable even in outpatient setting to accommodate the increase number of surgeries. Subsequently, improvement of modern anesthetic agents has matched with surgical expansion and contributed Ambulatory Anesthesia acquiring an important place in routine practice. Concurrently, such surgical demand has adjusted with an appropriate and matching modification of anesthetic techniques along with motivation of anesthesiologists. In many countries, anorectal surgical procedures are performed in outpatient settings ${ }^{3}$.

Hence, reduction of hospital stay is unexpected with the conventional method of spinal anesthesia for above purpose. ${ }^{4}$ Fast recovery from anesthesia is desirable ${ }^{5}$. However, sacral saddle block with low dose of local anesthetic is perfectly suitable for above purpose without involvement of motor nerves of lower limbs.

The sacral saddle block is a segmental block for the area of perineum and inner sides of thigh that would touch a saddle at the time of riding a horse and this corresponds to the area, innervated by sacral component of spinal roots $\left(\mathrm{S}_{1--} \mathrm{S}_{5}\right)^{6}$. These sacral segments are responsible for sensory and motor supply of posterior surface of lower limb with perineum and anal canal. Sensory components of $S_{1}-S_{5}$ are blocked first, motor ones are next to be blocked either completely or partially or remained unblocked, depending on amount of available drugs to act.

The motor and sensory activities of lower limbs depend on lumbosacral roots of the spinal cord extending from first lumbar spinal segment to fifth sacral spinal segments (L1 to S5). Similarly, the sympathetic supply to the lower limbs depends on neurones in the lateral horn of the lower three thoracic (T10, T11 and T12) and upper two lumbar (L1 L2) spinal cord segments and are responsible to control the hemodynamic status of lower limbs. The bilateral segmental block of the lumbosacral roots of spinal cord achieved by the low dose of the sacral spinal anesthesia through the second dorsal foramen of the sacrum provides more hemodynamic stability to patients. Generally, this procedure is accompanied with minimal chance of involvement of lower sympathetic outflow with expectation of undisturbed cardiovascular response by low dose intrathecal administration of local anesthetic. The maximal hemodynamic stability was noticed in this study.

The intrathecal caudal spread of local anesthetic due to hyperbaricity and gravity is impossible as penetration of subarachnoid space in sacral saddle block takes place at the bottom of dural sac. Concurrently, intrathecal cephalad spread of local anesthetic becomes possible to involve $S_{1}$ as small amount $(0.75 \mathrm{ml})$ of local anesthetic is injected in subarachnoid space. Due to injection at bottom of dural sac, immediate supine position of patients after intrathecal procedure does not disturb the accuracy and specificity of saddle block.

The spinal segments, extending $10^{\text {th }}$ thoracic to $2^{\text {nd }}$ lumbar $\left(\mathrm{T}_{10}-\mathrm{L}_{2}\right)$ are responsible for sympathetic innervations of lower limb, so the chance of hemodynamic disturbance in the process of sacral saddle block is rare and such is reflected in this study. 
Bilateral first two pairs of dorsal foramens are selected to locate the subarachnoid space within sacral canal, but sometimes it becomes difficult due to anomalies of foramina. These foramina may be smaller or even obliterated due to deposition of calcium around the rim. Usually, $2^{\text {rd }}$ dorsal foramen of sacrum is most preferable site to insert the spinal needle owing to termination of dural sac usually occurs at this level. The $1^{\text {st }}$ and $2^{\text {nd }}$ dorsal foramens of sacrum are the place of choice for easy introduction of spinal needle. The first two pairs of dorsal foramens are suitable to introduce needle to sacral subarachnoid space, although, it is not sure to get it at the first attempt, may need more or failed to get. In that event, it is better to leave it and attempt for another one.

The day care surgery is gaining the world-wide popularity due to its beneficial effects on reduction of hospital stay with lowering the hospital cost and chance of acquired infection ${ }^{8}$. Disruption of family life, sleep pattern disturbance and behavioral changes that are frequently noticed within patients, are equally avoided by day care surgery ${ }^{9}$. Children are excellent candidates for the day care surgery as they are usually healthy and free from systemic disease. ${ }^{10}$

At the end of surgery, the sacral saddle block is associated with early ambulation to move from the operating table to the transport trolley without help. In contrast, conventional saddle block is associated with motor block and patients' immobility. The sacral saddle block provides more accurate and specific segmental block for five sacral spinal segments (S1 to S5). This is technically easy to perform, simple to regulate the block height with minimal amount of drug and maximal hemodynamic stability. It is completely suitable for day care and ambulatory surgery in anorectal and perineal surgical procedures.

\section{Conclusion}

With hemodynamic stability and specific segmental involvement, sacral saddle block is better alternative to lumbar saddle block as day care and ambulatory surgery in anorectal surgical procedure even in outpatient setting with limited monitoring facilities.

\section{Reference}

[1]. Paria R, Surroy S, Majumder M, Paria A, Paria B, Das G. Sacral Spinal Anesthesia. Indian J Anesth. 2014; $58: 80-2$.

[2]. Senoglu N, Senoglu M, Oksus H, Gumusalan Y, Yuksel KZ, Zencirci B et al. Landmarks of the sacral hiatus for caudal epidural block: an anatomical study. Br J Anesth 2005; 95: 692-5.

[3]. Dahl V, Raeder J - Regional anaesthesia in ambulatory surgery. Curr Opin Anaesthesiol, 2003;16:471-476

[4]. Vaghadia Spinalanaesthea for outpatients: controversies and new techniques. Can J Anaesth, 1998;45:R64-R75.

[5]. Imbelloni LE, Gouveia MA - Unilateral spinal anesthesia with hypobaric bupivacaine. Rev Bras Anestesiol, 2002;52:542-548.

[6]. Paria R, Surroy S, Majumder M, Paria B, Sengupta S, Paria A. Sacral Saddle Block IOSR-JDMS 2014; 13(4) 39-40.

[7]. Abdulkareem IH. Day case surgery in Nigeria. Niger J Clin Pract 2011;14:383-9.

[8]. Gangadhar S, Gopal T, Sathyabhama, Paramesh K. Rapid emergence of day-care anaesthesia: A review. Indian J Anaesth 2012;56:336-41.

[9]. Upadhyaya M, Lander A. Day case surgery in children. Surgery 2013;31:140-4.

[10]. Erden IA, Pamuk AG, Ocal T, Aypar U. Parental satisfaction with pediatric day case surgery. Middle East J Anesthesiol 2006;18:1113-21.

\begin{tabular}{|c|c|c|}
\hline \multicolumn{3}{|c|}{$\begin{array}{l}\text { SENSORY AND MOTOR BLOCK PROFILE } \\
\end{array}$} \\
\hline TYPE OF BLOCK. & NERVE SUPPLY & EFFECT \\
\hline \multicolumn{3}{|l|}{ SENSORY BLOCK } \\
\hline Posterior surface of limb & $\mathrm{S}_{1,2,3}$ & blocked \\
\hline Anterior surface of lower limb & $\mathrm{L}_{1-5}$ & Not blocked \\
\hline \multicolumn{3}{|l|}{ MOTOR BLOCK. } \\
\hline \multicolumn{3}{|l|}{ Hip Joint. } \\
\hline \multicolumn{3}{|l|}{ Knee Joint. } \\
\hline Extension & $\mathrm{L}_{34}$ & Not blocked \\
\hline Flexion. & $\mathrm{L}_{5} \mathrm{~S}_{1}$ & Not blocked \\
\hline \multicolumn{3}{|l|}{ Ankle Joint. } \\
\hline Dorsi-flexion & $\mathrm{L}_{4,5}$ & Not blocked \\
\hline
\end{tabular}

\begin{tabular}{|l|l|}
\hline Table no. 2 DEMOGRAPHY AND HEMODYNAMIC PROFILE \\
\hline DEMOGRAPHY PROFILE & \\
\hline Age (year) & $49.71 \pm 12.22$ \\
\hline Height $(\mathrm{cm})$ & $153 \pm 3.96$ \\
\hline Weight(kg) & $58.23 \pm 9.71$ \\
\hline Sex(M \pm F) & $17: 13$ \\
\hline HEMODYNAMIC PROFILE & \\
\hline Systolic Blood Pressure.(mm Hg) & $124.45 \pm 7.23$ \\
\hline Oxygen Saturation. (\%) & $90.23 \pm 3.66$ \\
\hline Heart Rate (beats/min) & $99.65 \pm 0.23$ \\
\hline
\end{tabular}

